\title{
Analisis Gerak Teknik Pukulan Kizami Tsuki Jodan Perguruan Karate Dojo Kei Shin Kan SMPN 6 Medan Tahun 2019
}

\section{Motion Analysis of Kizami Tsuki Jodan's Punch Technique at Kei Shin Kan Dojo Karate College at SMPN 6 Medan in 2019}

\author{
Bremna Riko Ferdiyanto. $\mathbf{P}^{\mathbf{1}}$, Ibrahim ${ }^{2}$ \\ ${ }^{1,2}$ Fakultas Ilmu Keolahragaan, Universitas Negeri Medan \\ Email: bremnapasaribu8@gmail.com
}

\begin{abstract}
ABSTRAK
Tujuan penelitian ini untuk menganalisis dan mengetahui kebenaran Gerak Teknik Pukulan Kizami Tsuki Jodan pada Atlet Putra Perguruan Karate Dojo Kei Shin Kan SMPN 6 Medan. Metode penelitian yang digunakan adalah metode penelitian gabungan dengan mengkombinasikan antara dua metode penelitian kualitatif dan kuantitatif sehingga akan diperoleh data yang lebih komperhensif, valid, reliabel, dan objektif. Untuk menganalisis data, setiap atlet akan melaksanakan teknik pukulan Kizami Tsuki Jodan dan peneliti akan mengaplikasikan dengan menggunakan aplikasi software dartfish yang dimana pengambilan videonya terdapat lima sudut pengambilan dari samping kanan, dari samping kiri, dari depan dan dari atas, kemudian membandingkan pada atlet nasional setelah itu akan dilakukan penarikan kesimpulan dari data yang sudah diambil dari setiap atlet Dojo Kei Shin Kan SMPN 6 Medan. Hasil penelitian berdasarkan aplikasi software dartfish yang telah dianalisis dengan menggunakan 5 (lima) sudut kamera dapat disimpulkan bahwa masih banyak perbaikan kebenaran gerak yang perlu diperhatikan berdasarkan sudut-sudut dari setiap komponen yang dianalisis walaupun setiap kategori sudut setiap atlet menunjukan gerakan yang sudah hampir mendekati pembanding.
\end{abstract}

Kata Kunci : Analisis, Karate, Kizami Tsuki Jodan, software Dartfish.

\begin{abstract}
The purpose of this study was to analyze and find out the truth of the motion of the kizami tsuki jodan punch technique on male athletes at the kei shin kan karate dojo college of junior high school 6 Medan. The research method used is qualitative and quantitative research methods so that more comperhensive, valid, reliable, and objective data wil be obtained. To analyze the data, each athlete will carry out the kizami tsuki jodan stroke technique and the researcher will apply it using the Dartfish Software where there are five shooting angles from the right side, from the left side, from behind, from the front, and from above. Then comparing the national athletes, after that, conclusions will be drawn from the data that has been taken from each athlete of the Dojo Kei Shin Kan in state junior high school 6 Medan. The results of research based on the Dartsifh Software application that have been analyzed using five camera angles can be concluded that there are still many improvements to the correctness of motion that need to be considered based on the angular angle of each component being analyzed even though each category of the angle of each athlete shows a movement that is almost close to the comparison.
\end{abstract}

Keywords: Analysis, Karate, Kizami Tsuki Jodan, Dartfish Software 


\section{PENDAHULUAN}

Olahraga merupakan suatu aktifitas yang melibatkan tubuh secara menyeluruh serta jika dilakukan dengan benar dan berulang-ulang sangat bermanfaat baik pada kesehatan dan psikologis seseorang. olahraga juga mencakup tiga aspek penting yaitu kognitif, afektif, dan psikomotorik (Rozi, F., 2021). Tercpainya prestasi dalam olahraga merupakan usaha yang dilakukan melalui pembinaan usia dini baik dari kemampuan teknik, taktik dan strategi serta melalui pendekatan ilmiah.

Mendapatkan prestasi yang setinggitingginya diperlukan yang namanya usaha dan kerja keras yang latihannya sudah terencana dan terukur yang sesuai dengan cabang olahraga yang didalami. Olahraga (Fandayani, W., \& Sagitarius, S., 2019) Karate adalah salah satu cabang olahraga yang dapat membentuk ketahanan fisik, mental, emosi dan spritual serta dapat membangun sikap sportif bagi yang mempelajarinya (Simbolon, R. F., \& Siahaan, D., 2020). Seni bela diri karate pada dasarnya memiliki prinsip yang sama, yakni untuk melindungi diri dan bukan untuk memulai suatu pertarungan ataupun untuk melukai orang.

Hal ini dimungkinkan karena dalam penampilan olahraga karate bersifat tegas, efisien, logis dan simpel. Tegas karena diatur dengan kode etik baku yang berlandaskan doktrin disiplin kuat yang membentuk semacam hirarki yang bersifat setengah militer (Abdul Wahid, 2007;1).

Dalam karate dikembangkan teknik pukulan dan tendangan hingga ke tingkat mahir yaitu tingkat dimana seorang atlet dapat bergerak melakukan pukulan dan tendangan dengan cepat dan tepat (Rahayu, R., \& Sepdanius, E., 2020). Salah satunya adalah teknik pukulan kizami tsuki jodan.

Kizami Tsuki Jodan adalah salah satu serangan paling dasar dalam seni bela diri karate. Hal ini sebenarnya tidak lebih dari sebuah pukulan jab yang dilancarkan dari sisi depan. Dengan menggunakan kuda-kuda Zen Kutsu Dachi pukulan ini mengarah ke arah uluh hati dan ke kepala. Kizami Tsuki Jodan merupakan pukulan pemancing yang dapat mengalihkan perhatian lawan untuk melakukan teknik pukulan yang lain seperti gyaku tsuki dan sebagainya.

Dalam sebuah pertandingan banyak kareteka menggunakan pukulan ini, agar bisa memperoleh poin yuko berarti 1 apabila dilakukan dengan benar sesuai dengan kriteria yang sudah dibuat Federasi Olahraga Karateka Indonesia (FORKI).

Berdasarkan hasil observasi dan wawancara yang dilakukan sebanyak tiga 
kali pada tanggal 17, 20 dan 22 November 2018, pada atlet karate Dojo Kei Shin Kan SMPN 6 Medan, terdapat banyak pukulan tidak menggunakan putaran pinggang sehingga pukulan tidak bertenaga. Dalam observasi tersebut juga posisi kuda-kuda tumpuan yaitu kaki yang berada di depan dengan kuda-kuda Zenkutsu dachi peneliti melihat masih banyak yang kurang di tekuk sehingga jangkauan pukulan kurang mengenai sasaran yaitu kepala.

Sedangkan hasil wawancara yang dilakukan dengan asisten pelatih Senpai Berkat Anugerah Hutabarat dalam melakukan pukulan Kizami Tsuki atlet kurang memperhatikan tarikan tangan setelah melakukan pukulan dan tidak tepat dalam mengukur jangkauan pukulan dengan menggunakan kuda-kuda Zenkutsu dachi ketika melakukan serangan. Beberapa atlet tidak menggunakan putaran pinggang saat melakukan pukulan.

Kemungkinan pelatih dalam menganalisa gerak teknik hanya menggunakan indra penglihatan, yaitu mata dalam proes analisa gerak teknik pukulan atletnya. Hal ini terasa kurang maksimal dikarenakan mata mempunyai keterbatasan. Salah satu teknologi yang dapat membantu kinerja pelatih yaitu menggunakan kamera berupa video yang berfungsi untuk merekam atlet ketika melakukan teknik gerakan pukulan Kizami Tsuki Jodan, kemudian video tersebut dapat di analisis menggunakan sistem analisis perangkat lunak yang dapat membantu pelatih dalam menganalisa teknik gerakan atlet.

Berdasarkan informasi yang peneliti dapatkan dari pelatih dan pengamatan selama melakukan observasi di lapangan, peneliti ingin melakukan penelitian mengenai 'Analisis Gerak Teknik Pukulan Kizami Tsuki Jodan Perguruan Karate Dojo Kei Shin Kan SMPN 6 Medan 2019, dengan tujuan mengetahui teknik pukulan Kizami tsuki jodan yang benar dengan video perbandingan menggunakan aplikasi dartfish.

\section{METODE PENELITIAN}

Metode penelitian yang digunakan adalah metode penelitian gabungan dengan mengkombinasikan antara dua metode penelitian kualitatif dan kuantitatif sehingga akan diperoleh data yang lebih komperhensif, valid, reliabel, dan objektif (Asnaldi, A., 2015). Untuk menganalisis data, setiap atlet akan melaksanakan teknik pukulan Kizami Tsuki Jodan dan peneliti akan mengaplikasikan dengan menggunakan aplikasi software dartfish yang dimana pengambilan videonya terdapat lima sudut 
pengambilan dari samping kanan, dari samping kiri, dari depan dan dari atas, kemudian membandingkan pada atlet nasional setelah itu akan dilakukan penarikan kesimpulan dari data yang sudah diambil dari setiap atlet Dojo Kei Shin Kan SMPN 6 Medan

\section{HASIL DAN PEMBAHASAN}

Berdasarkan hasil penelitian yang dilakukan di Dojo Kei Shin Kan SMPN 6 Medan. Pada tanggal 29 bulan Januari Tahun 2020. Dengan jumlah atlet 3 orang yang dijadikan sebagai sampel pada penelitian ini. Metode memperoleh data pada penelitian ini menggunakan sofwer darfish dengan menjadikanatlet yang propesional sebagai atlet pembanding dan untuk mendapatkan analisis gerak sebagai penilaian kebenaran gerak.

Berikut ini merupakan data teknik pukulan Kizami Tsuki Jodan atlet propesional yang sudah dianalisis menggunakan sofware darfish yang dijadikan sebagai pembanding dan atlet dalam penelitian ini.

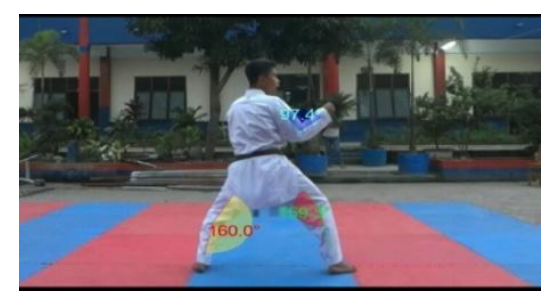

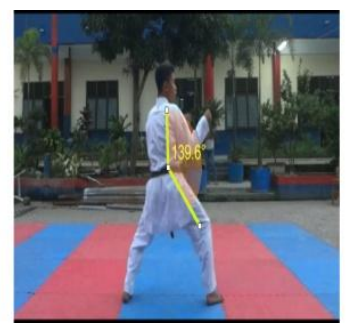

\section{Gambar 1. Pembanding (Muhammad Iqbal)}

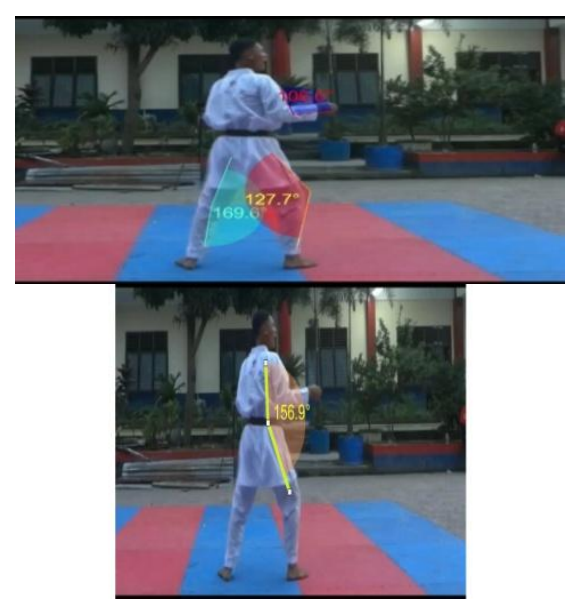

Gambar 2. Atlet 1 (Adi Kurniawan)

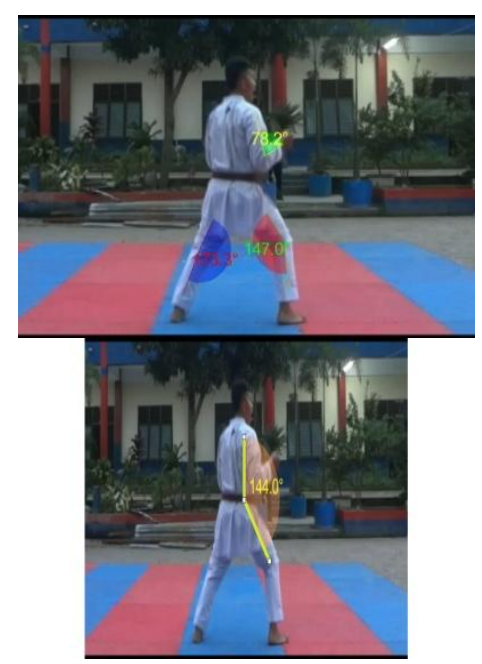

Gambar 3. Atlet 2 (Hendi Syahputra Butar-butar) 


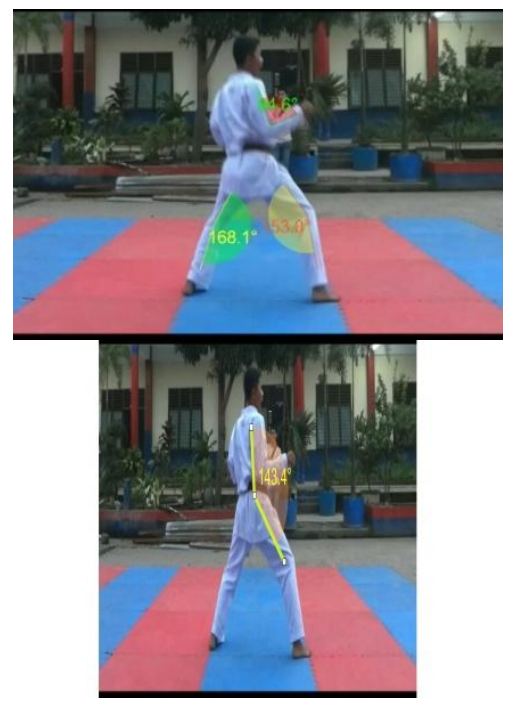

Gambar 4. Atlet 3 (Muhammad Aidil Febri)

\section{Tabel 1. Letak Posisi}

\begin{tabular}{lllllll}
\hline $\mathrm{N}$ & Ket & $\mathrm{Na}$ & $\mathrm{T}$. & $\mathrm{K}$. & $\mathrm{K}$, & $\mathrm{Bad}$ \\
$\mathrm{o}$ & & $\mathrm{ma}$ & $\mathrm{Kr}$ & $\mathrm{Kr}$ & $\mathrm{Kn}$ & an \\
\hline 1 & Pem & $\mathrm{G} .1$ & 97, & 15 & 16 & 139 \\
& $\begin{array}{l}\text { band } \\
\text { ing }\end{array}$ & & $4^{\circ}$ & $\begin{array}{l}9,3 \\
0^{\circ}\end{array}$ & $\begin{array}{l}0,0 \\
0^{\circ}\end{array}$ & $6^{\circ}$ \\
\hline 2 & $\begin{array}{l}\text { Atlet } \\
1\end{array}$ & $\mathrm{G} .2$ & 10 & 12 & 16 & 156 \\
& & & 6,4 & 7,7 & 9,6 & $9^{\circ}$ \\
& & & $\circ$ & $\circ$ & \\
\hline 3 & Atlet & G.3 & 78, & 14 & 17 & 144 \\
& 2 & & $2^{\circ}$ & $7^{\circ}$ & 3,3 & $\circ$ \\
& & & & & $\circ$ & \\
\hline 4 & Atlet & G.4 & 94, & 15 & 16 & 143 \\
& 3 & & $6^{\circ}$ & $3^{\circ}$ & 8,1 &, $4^{\circ}$ \\
& & & & & $\circ$ & \\
\hline
\end{tabular}

Berdasarkan hasil tabel di atas maka dapat dilihat bahwa untuk posisi tangan kiri atlet yang ke-3 (Muhammad Aidil Febri) kategori cukup baik dengan hasil sudut yang diperoleh sudah mendekati pembanding, untuk atlet ke-1 (Adi Kurniawan) dan atlet ke-2 (Hendi Syahputra Butar-butar) sudut yang diperoleh masih jauh dari pembanding sehingga masih perlu untuk dilakukan perbaikan gerak untuk posisi tangan kiri.

Posisi kaki kiri atlet yang ke-3 (Muhammad Aidil Febri) kategori cukup baik dengan hasil sudut yang diperoleh sudah mendekati pembanding, untuk atlet ke-1 (Adi Kurniawan) dan atlet ke-2 (Hendi Syahputra Butar-butar) sudut yang diperoleh masih jauh dari pembanding sehingga masih perlu untuk dilakukan perbaikan gerak untuk posisi kaki kiri.

Posisi kaki kanan atlet ke-1 (Adi Kurniawan) dan ke-3 (Muhammad Aidil Febri) kategori cukup baik dengan hasil sudut yang diperoleh sudah mendekati pembanding, atlet ke-2 (Hendi Syahputra Butar-butar) sudut yang diperoleh masih jauh dari pembanding sehingga masih perlu untuk dilakukan perbaikan gerak untuk posisi kaki kiri dan untuk sudut yang terakhir yaitu badan atlet ke-3 (Muhammad Aidil Febri) dan atlet ke-2 (Hendi Syahputra Butar-butar) sudah mendekati pembanding dan untuk atlet ke-1 (Adi Kurniawan) masih jauh dari pembanding sehingga perlu untuk dilakukan perbaikan gerak.

Berdasarkan hasil yang dilakukan oleh applikasi dartfish tersebut masih banyak atlet yang gerakan nya jauh dari pembanding, maka dari itu dibutuhkan perbaikan gerak dari setiap sudut kamera 
maupun dari posisi gerakan tangan para atlet. Yang dibutuhkan untuk memperbaiki gerakan atlet adalah dengan cara menambah porsi latihan mereka (Hudain, M. A., \& Ishak, M., 2020) dan memfokuskan ke otot yang mendominasi untuk melakukan gerakan tersebut (Same, R. J., 2021). Otot yang bekerja secara penuh dan harmonis akan menghasilkan teknik-teknik efektif dan kuat (Yonita, D., Sulaiman, I., \& Wijaya, Y. S., 2019).

\section{KESIMPULAN}

Berdasarkan hasil penelitian yang dilakukan dan sudah dibahas dalam bab sebelumnya maka peneliti menarik kesimpulan hasil analisis software dartfish menunjukanbahwa keseluruhan gerak pada tingkat kebenaran gerak teknik pukulan kizami tsuki jodan dalam kategori kurang. Penilaian ahli olahraga karate menunjukanbahwa keseluruhan gerak pada tingkat kebenaran gerak teknik pukulan kizami tsuki jodan masih dalam kategori kurang sehingga masih banyak yang harus diperbaiki.

\section{DAFTAR PUSTAKA}

Abdul. Wahid. 2007. Shotokan. Jakarta: PT Raja Grafindo Persada.

Asnaldi, A. (2015). Analisis Kondisi Fisik dalam Cabang Olahraga
Karate. Sport Science: Jurnal Ilmu Keolahragaan dan Pendidikan Jasmani, 24(29), 13-28.

Fandayani, W., \& Sagitarius, S. (2019). Analisis Teknik Tendangan Dominan terhadap Perolehan Poin pada Pertandingan Kumite Cabang Olahraga Karate. Jurnal Kepelatihan Olahraga, 11(1), 21-29.

Hudain, M. A., \& Ishak, M. (2020). Kontribusi Kecepatan Reaksi Tangan Dan Kekuatan Otot Lengan Terhadap Kecepatan Pukulan Gyaku Tsuki Chudan. SPORTIVE: Journal Of Physical Education, Sport and Recreation, 4(1), 46-52.

Rahayu, R., \& Sepdanius, E. (2020). Pengaruh Latihan Drop Push Up Terhadap Peningkatan Daya Ledak Otot Lengan Pada Atlet Karate Forki Kota Solok. JURNAL STAMINA, 3(6), 452-464.

Rozi, F. (2021). Analisis teknik dasar kudakuda zenkutsu dachi pada beladiri karate. Fair Play: Indonesian Journal of Sport, 1(1), 7-12.

Same, R. J. (2021). Pengaruh Latihan Memukul Memakai Beban Karet Terhadap Kecepatan Pukulan Dalam Olahraga Karate (Survey dalam Pembelajaran Mata Kuliah Karate). Publikasi Pendidikan, 11(2), 137-143.1

Simbolon, R. F., \& Siahaan, D. (2020). Pengembangan Instrumen Tes Kecepatan Tendangan Mawashi Geri Pada Cabang Olahraga Karate. JURNAL PRESTASI, 4(2), 49-54. 
Analisis Gerak Teknik Pukulan Kizami Tsuki Jodan Perguruan Karate Dojo Kei Shin Kan SMPN 6 Medan Tahun 2019

Yonita, D., Sulaiman, I., \& Wijaya, Y. S. (2019). Model Latihan Counter Attack Atlet Kumite Cabang Olahraga Karate. JTIKOR (Jurnal Terapan Ilmu Keolahragaan), 4(2), 99-106. 